\title{
Trombose de veia renal, doença de depósito de cadeias leves e nefropatia dos cilindros em
} paciente com mieloma múltiplo

\author{
Renal vein thrombosis, light-chain deposition disease and cast nephropathy in a multiple myeloma \\ patient
}

\section{Vilma Takayasua ${ }^{a}$ Silvana Maria Lovisolob ${ }^{b}$ Leonardo de Abreu Testagrossac ${ }^{c}$ Aloísio Felipe-Silva ${ }^{d}$}

Takayasu V, Lovisolo SM, Testagrossa LA, Felipe-Silva A. Trombose de veia renal, doença de depósito de cadeias leves e nefropatia dos cilindros em pacientes com mieloma múltiplo. Autopsy Case Rep [Internet]. 2011;1(2):41-8.

\section{RESUMO}

Mulher de 56 anos, hipertensa há 16 anos em tratamento, apresenta quadro de dor torácica e dispnéia há 3 dias. A investigação laboratorial demonstrou insuficiência renal aguda com indicação de hemodiálise. Após diálise, apesar de melhora clínico-laboratorial, apresentou fibrilação ventricular e parada cardiorrespiratória revertidas. Evoluiu oligúrica, sem déficits neurológicos. Foi iniciada investigação laboratorial para mieloma múltiplo que demonstrou hipogamaglobulinemia sem pico monoclonal na eletroforese de proteínas. Durante a investigação a paciente apresentou novo episódio de fibrilação ventricular e óbito. A autópsia demonstrou trombose de veia renal esquerda, mieloma múltiplo plasmacítico com acometimento de medula óssea, nefropatia por depósito difuso de cadeias leves kappa glomerular e tubular e nefropatia dos cilindros do mieloma. Este caso ilustra uma associação incomum entre nefropatia dos cilindros, nefropatia por depósito de cadeias leves e trombose de veia renal em paciente com mieloma múltiplo e insuficiência renal aguda.

Unitermos: Mieloma múltiplo; Autópsia; Trombose; Lesão renal aguda; Proteínas do mieloma.

\section{ABSTRACT}

\begin{abstract}
A 56-year-old woman presented with thoracic pain and dyspnea for 3 days. She had been under treatment for systemic arterial hypertension for 16 years. Laboratory investigation showed acute renal failure with indication for hemodialysis. After dialysis, despite improvements in clinical and laboratory parameters, she had an episode of ventricular fibrillation and cardiac arrest which was promptly reverted. She was still oliguric but without neurological deficits. A laboratory work up for multiple myeloma was started. Serum protein electrophoresis showed hypogammaglobulinemia without a monoclonal peak. While on laboratory work up, the patient had another episode of ventricular fibrillation and died. The autopsy showed left renal vein thrombosis, bone marrow involvement by a plasmacytic myeloma, light-chain deposition disease with diffuse glomerular and tubular involvement and also myeloma cast nephropathy. This case illustrates a rarely documented association between myeloma cast nephropathy, renal light-chain deposition disease and renal vein thrombosis in a multiple myeloma patient with acute renal failure.
\end{abstract}

Keywords: Multiple myeloma; Autopsy; Thrombosis; Acute kidney injury; Myeloma proteins.

a Divisão de Clínica Médica do Hospital Universitário - Universidade de São Paulo, São Paulo/SP, Brasil.

b Serviço de Anatomia Patológica do Hospital Universitário - Universidade de São Paulo, São Paulo/SP, Brasil.

${ }^{c}$ Divisão de Anatomia Patológica do Hospital das Clínicas da Faculdade de Medicina - Universidade de São Paulo, São Paulo/SP, Brasil.

d Serviço de Anatomia Patológica do Hospital Universitário - Universidade de São Paulo, São Paulo/SP, Brasil. 


\section{Relato de Caso}

Mulher de 56 anos, portadora de hipertensão arterial sistêmica (HAS) e hipotireoidismo em uso regular de propranolol, losartan, furosemida e levotiroxina procurou serviço médico com queixa de dor torácica à esquerda, dispnéia, ortopnéia e tosse há três dias. Não era portadora de diabetes ou qualquer outra doença. Negava tabagismo ou internações prévias. O exame físico mostrava paciente em regular estado geral, descorada e dispneica. Pressão arterial (PA) de $140 \times 78 \mathrm{mmHg}$, Pulso de 100 bpm, Freqüência respiratória de 28 ipm. Presença de crepitação em bases pulmonares e discreto edema de membros inferiores. Exame cardíaco e abdominal sem alterações.

Os exames laboratoriais iniciais (Tabela 1) revelaram anemia, níveis elevados de uréia e crea- tinina e hiperpotassemia.

O eletrocardiograma era normal. O ecocardiograma mostrou aumento do átrio esquerdo, hipertrofia discreta do ventrículo esquerdo com contração normal (fração de ejeção de $59 \%$ ). A valva aórtica estava espessada, com refluxo discreto. A valva mitral apresentava refluxo importante e a valva tricúspide refluxo moderado. $O$ gradiente VD-AD era de $58 \mathrm{mmHg}$.

A radiografia de tórax mostrava pequeno derrame pleural à esquerda.

A análise urinária revelou proteinúria $(+++)$ e sangue oculto $(++)$. O sedimento urinário mostrava 32.000 leucócitos $/ \mathrm{ml}$ e 57.000 hemácias $/ \mathrm{ml}$. Cilindros e cristais não foram detectados. A cultura de urina mostrou crescimento de mais de 100.000

Tabela 1 - Dados laboratoriais obtidos durante investigação diagnóstica*

\begin{tabular}{|c|c|c|c|}
\hline & Valor inicial & Pós-diálise & Valor de referência \\
\hline $\mathrm{Hb} / \mathrm{Ht}$ & $8,4 / 26$ & & $12,3-15,3(\mathrm{~g} \%) / 36,0-45,0(\%)$ \\
\hline Leucócitos & 9500 & & $4,4-11,3\left(\times 10^{3} / \mathrm{mm}^{3}\right)$ \\
\hline Bastonetes & 0 & & $1-5(\%)$ \\
\hline Segmentados & 61 & & $45-70(\%)$ \\
\hline Eosinófilos & 5 & & $1-4(\%)$ \\
\hline Basófilos & 0 & & $0-2,5(\%)$ \\
\hline Linfócitos & 29 & & $18-40(\%)$ \\
\hline Monócitos & 5 & & $2-9(\%)$ \\
\hline Plaquetas & 314.000 & & $150-400\left(\times 10^{3} / \mathrm{mm}^{3}\right)$ \\
\hline $\mathrm{U} / \mathrm{Cr}$ & $156 / 7,7$ & $64 / 4,1$ & $10-50 / 0,4-1,3(\mathrm{mg} / \mathrm{dl})$ \\
\hline $\mathrm{Na} / \mathrm{K}$ & $137 / 7,5$ & $137 / 3,9$ & $135-146 / 3,5-5,0(\mathrm{mEq} / \mathrm{l})$ \\
\hline Cálcio & 1,25 & 1,23 & $1,11-1,40(\mathrm{mmol} / \mathrm{l})$ \\
\hline $\mathrm{Mg} / \mathrm{P}$ & $2,6 / 6,1$ & $1,7 / 4,5$ & $1,6-2,6 / 2,5-4,8(\mathrm{mg} / \mathrm{dl})$ \\
\hline AST/ALT & $23 / 24$ & & $10-31 / 9-36(\mathrm{U} / \mathrm{l})$ \\
\hline Proteína total & 6,4 & & $6,0-8,0(\mathrm{~g} \%)$ \\
\hline Albumina & 2,83 & & $3,5-5,0(\mathrm{~g} \%)$ \\
\hline Alfa-1 & 0,42 & & $0,1-0,4(g \%)$ \\
\hline Alfa-2 & 1,5 & & $0,4-1,2(g \%)$ \\
\hline Betaglobulina & 1,26 & & $0,5-1,1(g \%)$ \\
\hline Gamaglobulina & 0,39 & & $0,5-1,6(g \%)$ \\
\hline Troponina & & 1,07 & $<0,06 \mathrm{ng} / \mathrm{ml}$ \\
\hline CKMB & & 9,02 & $<5,0 \mathrm{ng} / \mathrm{ml}$ \\
\hline VHS & 130 & & $<20 \mathrm{~mm} / 1 \mathrm{~h}$ \\
\hline PCR & 5 & & $<5 \mathrm{mg} / \mathrm{l}$ \\
\hline FAN (HEP II) & não reagente & & até $1 / 80$ \\
\hline $\mathrm{C} 3 / \mathrm{C} 4$ & $115 / 79$ & & $90-180 / 10-40 \mathrm{mg} / \mathrm{dl}$ \\
\hline
\end{tabular}

*Todas as dosagens em sangue ou soro. Valores alterados estão em negrito.

$\mathrm{Hb}$ : Hemoblogina; Ht: Hematócrito; U:Uréia; Cr:creatinina; Alfa-1: alfa-1-globulina; Alfa-2: alfa-2-globulina; VHS: velocidade de hemossedimentação; PCR: Proteína C reativa; FAN: Fator antinúcleo; C3 e C4: Frações C3 e C4 do complemento. 
UFC/ml de Escherichia coli multissensível.

A ultrassonografia de vias urinárias mostrava rins tópicos, com formas, contornos e dimensões normais e simétricas. O parênquima renal tinha espessura preservada, porém com acentuação da diferenciação córtico-medular e certa hipoecogenicidade das pirâmides renais que sugeriam possível nefropatia parenquimatosa aguda.

Frente ao diagnóstico de insuficiência renal foram realizadas medidas iniciais para hiperpotassemia e indicada hemodiálise. Também foi prescrito ceftriaxone para tratamento da infecção urinária.

Durante passagem de catéter para hemodiálise a paciente apresentou edema agudo de pulmão relacionado à hipertensão e hipervolemia, o qual foi controlado com furosemida e anlodipina. Foi afastada a possibilidade de infarto do miocárdio.

A paciente foi submetida a uma sessão de hemodiálise sem intercorrências com perda de 3000 ml, estabilização volêmica e eletrolítica (Tabela 1). Entretanto, apresentou episódio de fibrilação ventricular (FV) e parada cardiorrespiratória (PCR) que foi revertida após três minutos com desfibrilação elétrica. Transferida para a unidade de terapia intensiva com amiodarona, atenolol, anlodipina e levotiroxina, evoluiu sem déficits neurológicos e oligúrica. Foi mantido o tratamento dialítico.
A paciente permaneceu em UTI por um total de 11 dias. Durante a internação houve queixa de dorsalgia e dor em gradil costal à movimentação e sensação de estalos paraesternais. A radiografia de tórax mostrou fraturas de costelas que foram atribuídas às manobras de ressuscitação cardiopulmonar.

A investigação da insuficiência renal revelou pesquisa negativa para fator anti-núcleo (FAN) e níveis normais de complemento e marcadores de inflamação (proteína $C$ reativa e velocidade de hemossedimentação). Foi observada hipoalbuminemia não nefrótica e hipogamaglobulinemia sem pico monoclonal à eletroforese de proteínas séricas. Foi indicada biópsia renal e mielograma, para confirmação da hipótese de mieloma múltiplo, porém no décimo segundo dia de internação a paciente apresentou novamente FV e PCR que evoluiu para óbito. A imunofixação do soro, realizada após o óbito da paciente, evidenciou uma fração monoclonal entre alfa-2-globulinas e beta-globulinas identificada como cadeia leve kappa.

\section{Autópsia}

A autópsia confirmou infiltração difusa da medula óssea por proliferação monoclonal de plasmócitos maduros, CD138 positivos à imunoistoquímica (marcador plasmocitário) e com predomínio de cadeia leve kappa (Figura 1). Não foi observada infiltração neoplásica em outros órgãos.

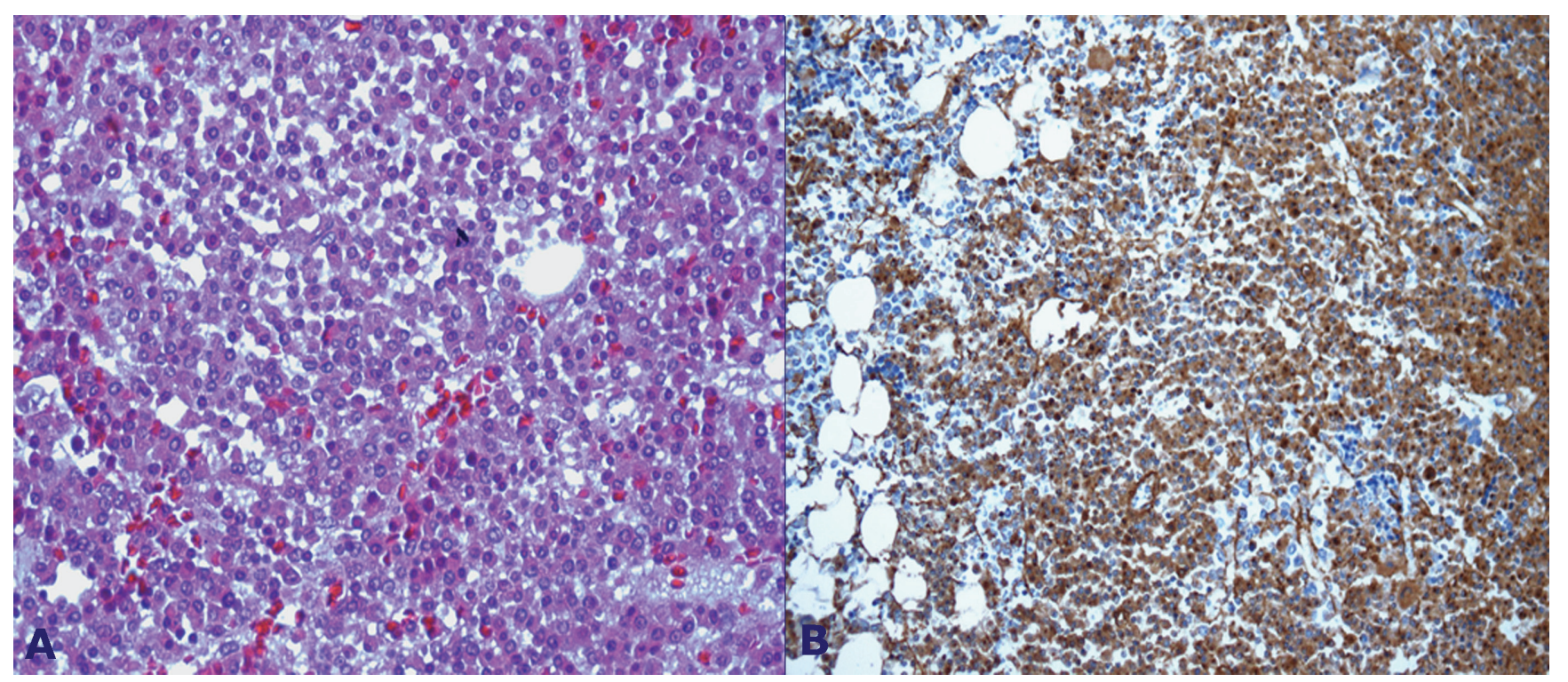

Figura 1 - A - Fotomicrografia da medula óssea infiltrada difusamente por plasmócitos maduros (HE, 400x). B - Imunoistoquímica de medula óssea com positividade difusa para cadeia leve kappa (200x). 
Observou-se derrame pleural bilateral e pericárdico de aspecto seroso, em moderada quantidade, relacionados à hipervolemia e insuficiência renal. Os pulmões apresentavam congestão. O coração apresentava aumento de volume por hipertrofia concêntrica do ventrículo esquerdo e dilatação do átrio esquerdo, compatíveis com hipertensão arterial sistêmica. As coronárias eram normais. A mi-
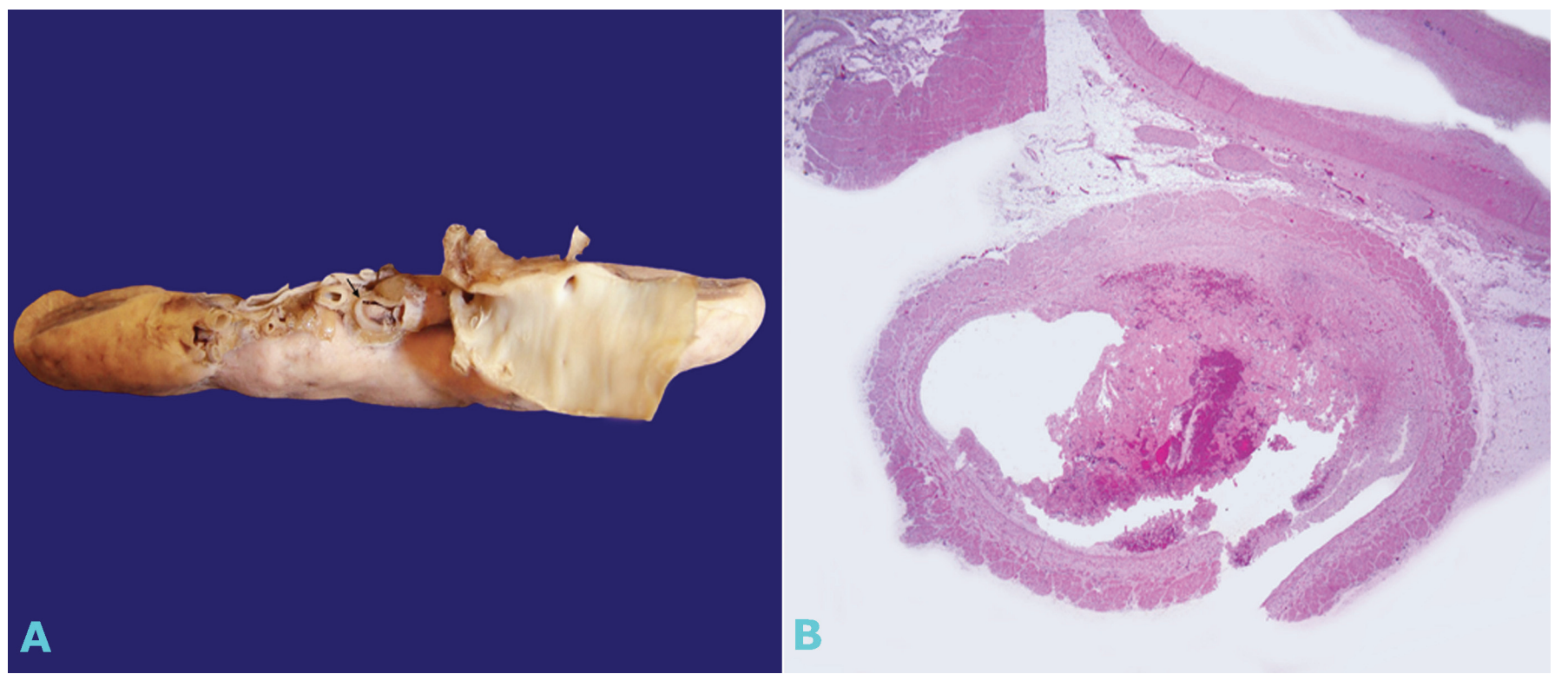

Figura 2 - A - Aspecto macroscópico de trombo em veia renal (seta), vista a partir do hilo. B - Fotomicrografia de trombo em veia renal (HE, 40x).

A análise do tecido renal revelou glomerulopatia por cadeias leves do tipo kappa, caracterizada por glomérulos aumentados em volume, com hipercelularidade mesangial e expansão global e difusa da matriz mesangial devido à deposição de material eosinofílico que por vezes se acumulava em alças croscopia confirmou apenas hipertrofia miocárdica sem evidências de infiltração neoplásica ou depósitos patológicos.

Os rins apresentavam forma e volume preservados. Foi identificado trombo segmentar e semi-oclusivo da veia renal esquerda (Figura 2). glomerulares formando nódulos circundados por células mesangiais (Figura 3 ), e também espessava a cápsula de Bowman com extensão à região peri-hilar, envolvendo as arteríolas glomerulares. O material eosinofílico se impregnava pela prata, era PAS-positivo (Figura 4) e Vermelho Congo negativo.

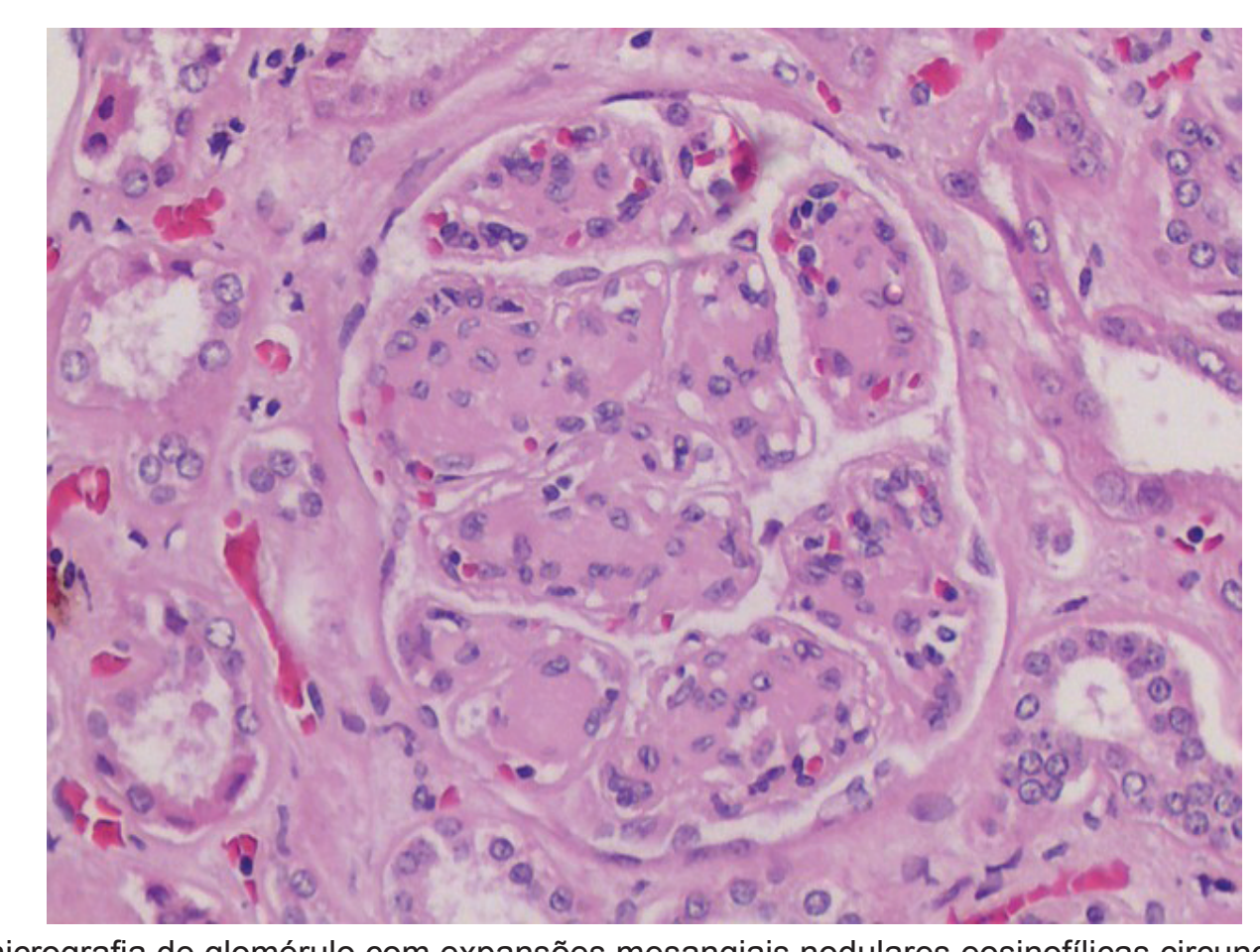

Figura 3 - Fotomicrografia de glomérulo com expansões mesangiais nodulares eosinofílicas circundadas por hiperce-

lularidade mesangial (HE, 400x). 


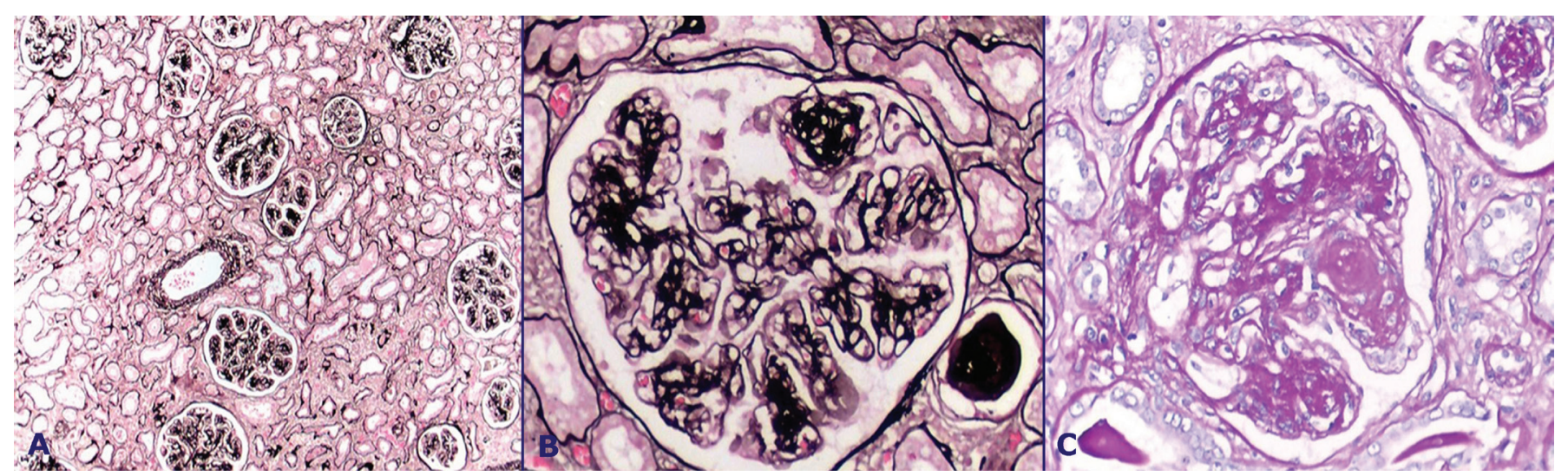

Figura 4 - Fotomicrografias demonstrando: A - Glomérulos aumentados com distribuição difusa no córtex renal (PAMS, 100x); B - Glomérulo com impregnação dos nódulos pela prata (PAMS, 400x); C - Glomérulo demonstrando nódulos PAS-positivos (PAS, 400x).

Observou-se ainda nefropatia do cilindro de cadeias leves no compartimento tubular, caracterizada por espessamento difuso das membranas basais e, em algumas áreas, túbulos dilatados contendo cilindros eosinofílicos, predominantemente com aspecto homogêneo e lamelados, porém oca- sionalmente granulosos e com reação inflamatória neutrofilica e gigantocelular. Esses cilindros eram PAS positivos, impregnavam-se fracamente pela prata, com coloração marrom-amarelada, e eram policromáticos quando corados pelo tricrômico de Masson (Figura 5).

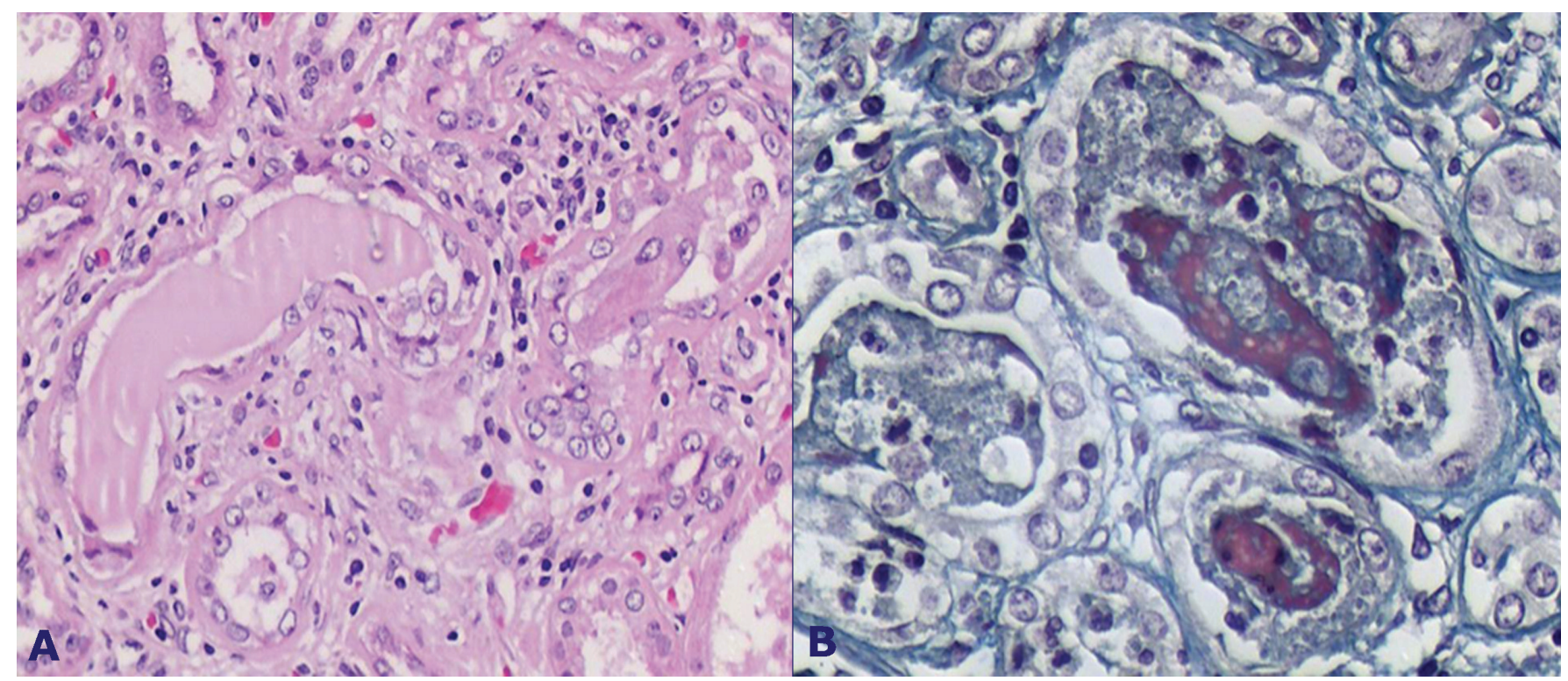

Figura 5 - A - Fotomicrografia de túbulo renal contendo cilindro luminal eosinofílico (HE, 200x); B - Fotomicrografia de cilindro de aspecto "quebradiço" e policromático (Tricrômico de Masson, 400x).

A imunofluorescência direta resultou negativa para a deposição de imunoglobulinas e fatores do complemento (IgA, IgG, IgM, C1q e C3), bem como para cadeia leve lambda. Entretanto, observou-se intensa deposição de cadeia leve kappa, com padrão linear, difusamente distribuída em membranas basais, tufos glomerulares e cilindros tubulares (Figura 6).

Não foram observadas alterações histológicas ou depósitos anômalos nos demais órgãos e tecidos. 


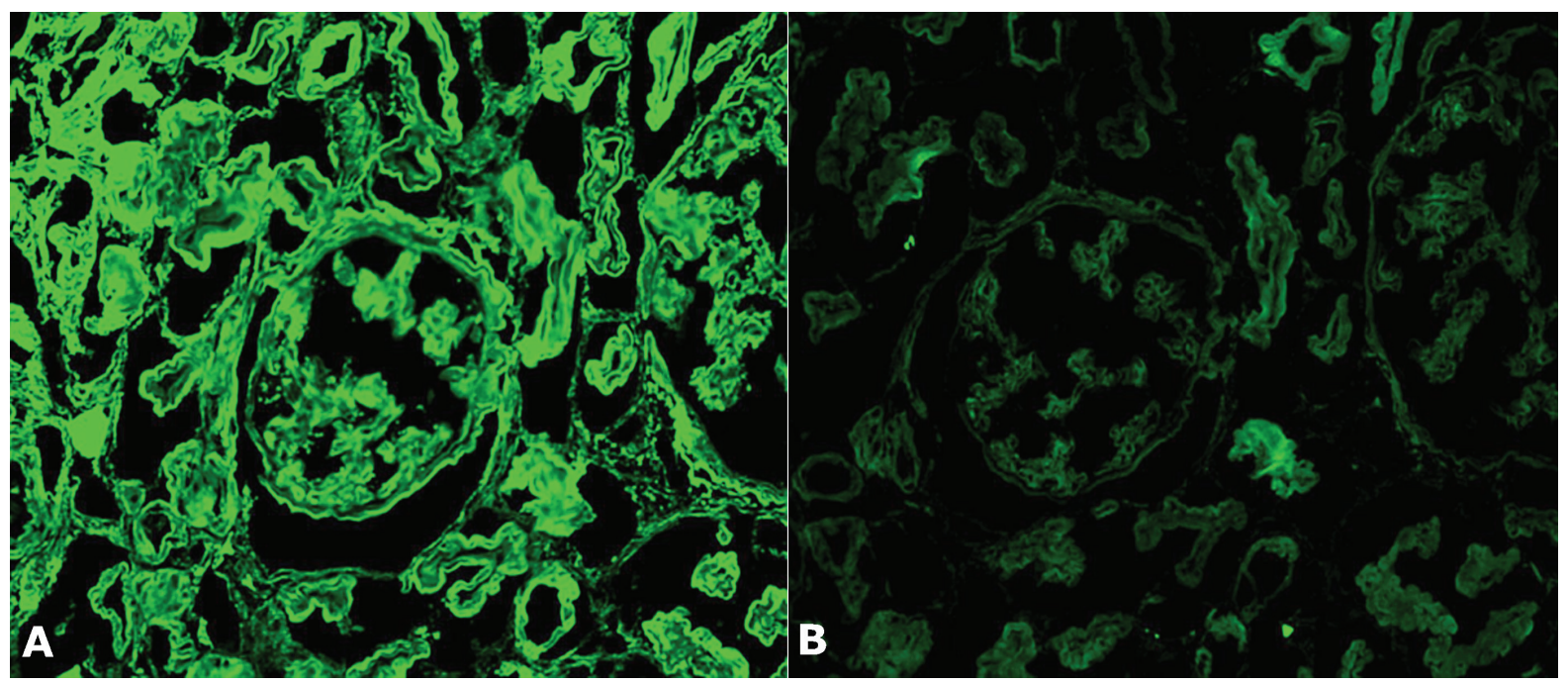

Figura 6 - A - Fotomicrografia de imunofluorescência direta para cadeia kappa demonstrando positividade intensa, difusa, em membranas basais de túbulos e glomérulos, e em nódulos glomerulares; B - Imunofluorescência direta para cadeia lambda negativa.

\section{DISCUSSÃO}

O mieloma múltiplo (MM) deve ser incluído no diagnóstico diferencial de todo paciente que apresenta insuficiência renal sem etiologia definida. $^{1,2}$ O MM é caracterizado pela proliferação neoplásica clonal de plasmócitos que produzem proteínas monoclonais $(\mathrm{M})$ detectáveis no sangue ou na urina. As principais manifestações clínicas do MM decorrem diretamente da proliferação neoplásica ou do dano tecidual causado pela proteína monoclonal, e incluem dor e/ou fraturas ósseas, insuficiência renal, anemia, susceptibilidade à infecção, hiperviscosidade e hipercalcemia. As manifestações clínicas mais frequentes são anemia $(80 \%)$, dor óssea $(70 \%)$, insuficiência renal $(25 \%)$, fadiga / astenia (32\%), hipercalcemia $(28 \%)$ e perda de peso (24\%). Outras manifestações menos frequentes incluem parestesia, hepatomegalia, esplenomegalia, linfadenoapatia e febre..$^{3-5}$

Neste caso a paciente apresentava insuficiência renal aguda associada a anemia e dor torácica, com detecção de fraturas de arcos costais a posteriori, com investigação inicial para a hipótese de MM.

Para o diagnóstico de $\mathrm{MM}$, além do quadro clínico, é necessário demonstrar a proliferação do clone plasmocitário na medula óssea (plamocitose $>10 \%$ ) e a presença da proteína $M$, que pode ser detectada pela eletroforese de proteínas (EFP) do soro ou urina (alíquota da urina de 24 horas). ${ }^{3-5}$ Ao se suspeitar de bandas anormais à EFP deve- se realizar a imunofixação para caracterização de seu tipo.

A EFP irá demonstrar um pico de base estreita (pico monoclonal) em $82 \%$ dos pacientes com mieloma. A adição de imunofixação sérica aumenta a sensibilidade para 93\%. Quando a eletroforese de proteínas e imunofixação da urina são realizadas a sensibilidade aumenta para $97 \%$. Os demais $3 \%$ dos pacientes que não apresentam proteína $M$ detectável são considerados portadores de mieloma não secretor. ${ }^{4,5}$

A imunofixação sérica é o padrão ouro para a detecção de proteína $M .{ }^{5} \mathrm{O}$ tipo mais comum é a IgG em $55 \%$ dos casos seguida por $\lg A$ em $22 \%$, somente cadeia kappa ou lambda em 18\%, IgD ou IgE em $2 \%$, biclonal em $2 \%$ e IgM em menos de $1 \%$ dos casos. Aproximadamente $2 / 3$ dos pacientes com proteína $M$ no soro tem cadeia leve na urina. A pesquisa tradicional de proteína de Bence Jones (cadeia leve) na urina por termoprecipitação não é mais recomendada por ser artesanal e de difícil padronização, com resultados falso-negativos em quase $50 \%$ dos $\mathrm{MM}$ de cadeia leve. ${ }^{1}$

A detecção isolada de somente uma cadeia leve no soro ou urina, na ausência de cadeia pesada, caracteriza o MM de cadeia leve. Alguns achados laboratoriais auxiliam esse diagnóstico: a proteína total sérica é normal ou baixa, hipogama- 
globulinemia é comum, a cadeia leve monoclonal na urina está sempre presente e muitos pacientes não apresentam componente monoclonal na EFP sérica, pois as cadeias leves são rapidamente filtradas pelos rins, impossibilitando sua demonstração. Aproximadamente $60 \%$ dos pacientes inicialmente classificados como não secretores apresentam cadeias leves monoclonais livres quando são utilizados ensaios específicos para cadeias leves livres. ${ }^{4}$

Esta paciente apresentava hipogamaglobulinemia sem pico monoclonal na EFP, com imunofixação realizada após o óbito confirmando a presença de cadeia leve monoclonal kappa sérica, caracterizando, portanto, um MM de cadeia leve. O mielograma e/ou biópsia de medula óssea seriam os próximos exames para confirmar o diagnóstico de MM.

A doença renal é observada frequentemente nos portadores de MM e, quando presente, reflete doença mais grave, devendo ser prontamente reconhecida e tratada. Está presente em 20 a $50 \%$ dos casos na ocasião do diagnóstico. No MM de cadeia leve, esta proporção sobe para $65 \%$. ${ }^{1,3}$ A lesão renal é causada na maioria dos casos pela toxicidade das cadeias leves monoclonais nas estruturas renais, principalmente nos túbulos (nefropatia dos cilindros de cadeias leves ou rim do mieloma). O mecanismo de lesão envolve obstrução e aumento da pressão intratubular com redução da filtração glomerular e dano às células tubulares causado pelo efeito tóxico direto da cadeia leve. Na nefropatia dos cilindros a proteinúria geralmente é negativa ou fraca. ${ }^{1,6-8}$ Menos frequentemente, a lesão renal do MM ocorre nos glomérulos (amiloidose e doença de depósito de cadeias de imunoglobulinas), com proteinúria geralmente maciça. Outros fatores que contribuem e agravam a lesão renal são hipercalcemia, desidratação, drogas nefrotóxicas, e uso de contrastes. ${ }^{1}$

O depósito de cadeias leves nos glomérulos e em outros tecidos pode ocorrer na forma de amiloidose primária ou de doença de depósito de cadeia leve. $\mathrm{Na}$ amiloidose primária, as cadeias leves circulantes, geralmente do tipo lambda, são captadas e parcialmente metabolizadas, precipitando-se em estruturas fibrilares identificáveis pela coloração do vermelho do congo, frequentemente na membrana basal e no mesângio. Na doença de depósito de cadeia leve os fragmentos protéicos circulantes, geralmente do tipo kappa, não formam fibrilas e os depósitos não se coram pelo vermelho do congo. A característica clinica da lesão glomerular é a síndrome nefrótica. 1,6,7

Apesar da presença de trombose de veia renal à autópsia, não foi possível caracterizar síndrome nefrótica nesta paciente, embora estes dois eventos estejam frequentemente associados. A proteinúria importante detectada no exame de urina I é de interpretação duvidosa frente ao quadro de infecção urinária. Ainda, como a paciente permaneceu oligúrica, a quantificação da proteinúria de 24 horas ficou prejudicada. Adicionalmente, apresentava hipogamaglobulinemia com proteína sérica total dentro da faixa normal. Assim, uma eventual perda urinária de proteínas anticoagulantes em função da glomerulopatia ou mesmo uma hiperviscosidade sanguínea relacionada ao MM seriam explicações improváveis para a trombose de veia renal neste caso. Neste contexto, a trombose de veia renal detectada à autópsia deve estar mais relacionada a outros fatores pró-trombóticos intrínsecos ao paciente com MM. ${ }^{8,9}$ Não encontramos relatos especificamente de trombose de veia renal associada ao rim do mieloma, mesmo em grandes séries de autópsias. ${ }^{10,11}$

A nefropatia do cilindro pode ocorrer em combinação à lesão glomerular do mieloma, como neste caso. ${ }^{12,13}$ Quando combinadas, entretanto, em quase $70 \%$ das vezes os glomérulos estão normais à microscopia óptica e o diagnóstico é obtido pela imunofluorescência ou microscopia eletrônica. ${ }^{14}$

A presença de falência renal aumenta o risco de morte principalmente nos primeiros meses após o diagnóstico, pois representa doença mais avançada e com maior risco de complicações. A taxa de mortalidade nos dois primeiros meses após o diagnóstico é de $30 \%$. A sobrevida média dos que ultrapassam este período é de dois anos, e 1/3 desses sobrevive três anos. Como estudos recentes relatam sobrevida média para pacientes com MM maior que cinco anos, um diagnóstico precoce e tratamento apropriado com quimioterápicos específicos, hemodiálise com permeabilidade a proteínas e tratamento de suporte são fundamentais para tentar melhorar o prognóstico dos portadores de MM com doença renal. ${ }^{1,2,15,16}$ 


\section{REFERÊNCIAS}

1. Neuwirt H, Rudnicki M, Schramek H, Mayer G. Monoclonal light chains and the kidney. Nephrol Rev. 2011; 3:e3:13-22.

2. Dimopoulos MA, Kastritis E, Rosinol L, Blade J, Ludwig $\mathrm{H}$. Pathogenesis and treatment of renal failure in multiple myeloma. Leukemia. 2008;22(8):1485-93.

3. Bladé J, Rosiñol L. Complications of multiple myeloma. Hematol Oncol Clin N Am. 2007;21(6):1231-46.

4. Kyle RA, Gertz MA, Witzig TE, Lust JA, Lacy MQ, Dispenzieri A et al. Review of 1027 patients with newly diagnosed multiple myeloma. Mayo Clin Proc. 2003;78(1):21-33.

5. Lin P. Plasma cell myeloma. Hematol Oncol Clin North Am. 2009;23(4):709-27.

6. Buxbaum JN, Chuba JV, Hellman GC, Solomon A, Gallo GR. Monoclonal immunoglobulin deposition disease: light chain and light and heavy chain deposition diseases and their relation to light chain amyloidosis. Clinical features, immunopathology, and molecular analysis. Ann Intern Med. 1990;112(6):455-64.

7. Dimopoulos MA, Terpos E, Chanan-Khan A, Leung N, Ludwig $\mathrm{H}$, Jagannath $\mathrm{S}$ et al. Renal impairment in patients with multiple myeloma: a consensus statement on behalf of the International Myeloma Working Group. J Clin Oncol. 2010;28(33):4976-84.

8. Kristinsson SY. Thrombosis in multiple myeloma. Hematology Am Soc Hematol Educ Program. 2010;2010:437-44.

9. Asghar M, Ahmed K, Shah SS, Siddique MK, Dasgupta P,
Khan MS. Renal vein thrombosis. Eur J Vasc Endovasc Surg. 2007; 34(2):217-23.

10. Iványi B. Frequency of light chain deposition nephropathy relative to renal amyloidosis and Bence Jones cast nephropathy in a necropsy study of patients with myeloma. Arch Pathol Lab Med. 1990;114(9):986-7.

11. Herrera GA, Joseph L, Gu X, Hough A, Barlogie B. Renal pathologic spectrum in an autopsy series of patients with plasma cell dyscrasia. Arch Pathol Lab Med. 2004;128(8):875-9.

12. Lorenz EC, Sethi S, Poshusta TL, Ramirez-Alvarado M, Kumar S, Lager DJ, Fervenza FC and Leung N.Renal failure due to combined cast nephropathy, amyloidosis and light-chain deposition disease. Nephrol Dial Transplant. 2010;25(4):1340-3.

13. Qian Q, Leung N, Theis JD, Dogan A, Sethi S. Coexistence of myeloma cast nephropathy, light chain deposition disease, and nonamyloid fibrils in a patient with multiple myeloma. Am J Kidney Dis. 2010;56(5):971-6.

14. Gokden N, Cetin N, Colakoglu N, Kumar J, Abul-Ezz S, Barlogie B, Liapis $\mathrm{H}$, Walker PD. Morphologic manifestations of combined light-chain deposition disease and light-chain cast nephropathy. Ultrastruct Pathol. 2007;31(2):141-9.

15. Cockwell P, Hutchison CA. Management options for cast nephropathy in multiple myeloma. Curr Opin Nephrol Hypertens. 2010;19(6):550-5.

16. Palumbo A, Anderson K. Multiple myeloma. N Engl J Med. 2011;364(11):1046-60.

\section{Conflito de interesse: Não}

Submetido em: 09 de Junho de 2011

Aceito em: de Junho de 2011

Correspondência: Divisão de Clínica Médica

Av. Prof. Lineu Prestes, 2565 - Cidade Universitária - São Paulo - SP - Brasil il

CEP: 05508-000 - Tel.: +55.11. 3091.9379

E-mail: vilmatakayasu@uol.com.br 